\title{
Flora das cangas da Serra dos Carajás, Pará, Brasil: Hymenophyllaceae
}

Flora of the cangas of Serra dos Carajás, Pará, Brazil: Hymenophyllaceae

Julieta Pallos ${ }^{1,3}$, Luiz Armando de Araújo Góes-Neto ${ }^{1}$ \& Alexandre Salino ${ }^{2}$

\begin{abstract}
Resumo
Este estudo trata os táxons de Hymenophyllaceae registrados nas cangas da Serra dos Carajás, estado do Pará, com descrições, ilustrações, distribuição geográfica e comentários. Na área estudada foram registradas cinco espécies distribuídas em dois gêneros, Trichomanes accedens, T. crispum, T. elegans, T. pinnatum e Vandenboschia radicans.
\end{abstract}

Palavras-chave: Amazônia, rocha ferruginosa, samambaias, Trichomanes, Vandenboschia.

\begin{abstract}
This study treats Hymenophyllaceae taxa recorded in cangas of Serra dos Carajás, Pará state, with descriptions, illustrations, geographical distribution, and comments. In the study area two genera and five species were registered, Trichomanes accedens, T. crispum, T. elegans, T. pinnatum, and Vandenboschia radicans.
\end{abstract}

Key words: Amazonia, ironstone, ferns, Trichomanes, Vandenboschia.

\section{Hymenophyllaceae}

Hymenophyllaceae Gaudich. é uma família monofilética, possui duas subfamílias, nove gêneros e cerca de 434 espécies (PPG I 2016), com distribuição principalmente pantropical e sul-temperada (Smith et al. 2006). São plantas terrícolas, rupícolas ou epífitas; caule reptante, ascendente ou ereto, por vezes cespitoso; lâminas geralmente com uma única camada de células, sem cutícula ou estômatos; frondes estéreis e férteis monomorfas a acentuadamente dimorfas, não articuladas com o rizoma, com ou sem tricomas e sem escamas; nervuras livres ou raramente anastomosadas, com ou sem falsas vênulas. Indúsio livre ou imerso no tecido laminar, tubular, campanulado, infundibuliforme ou bivalvado; esporos clorofilados. No Brasil ocorrem ca. 87 espécies, sendo a Amazônia o bioma mais diversificado, com 61 espécies (Prado et al. 2015). Na Serra dos Carajás foram registradas 15 espécies (Arruda 2014), das quais cinco ocorrem em formações rupestres de canga.

\section{Chave de identificação dos gêneros de Hymenophyllaceae das cangas da Serra dos Carajás}

1. Caule curto-reptante, ascendente, ereto ou cespitoso; pecíolo sem ala, ou se alado, esta é inconspícua; pinas ou segmentos simétricos; margem da lâmina glabra ou com tricomas 1. Trichomanes

1'. Caule longo-reptante; pecíolo conspicuamente alado desde a base; pinas ou segmentos assimétricos; margem da lâmina sempre glabra 2. Vandenboschia

\section{Trichomanes L.}

Plantas terrícolas, rupícolas ou epífitas. Caule curto a longo-reptante, ascendente, ereto ou cespitoso. Frondes monomorfas, subdimorfas ou fortemente dimorfas; pecíolo alado ou não, glabro ou com tricomas; lâmina simples a 4-pinada, glabra ou com tricomas; venação livre, furcada, catadrômica ou anadrômica, com ou sem falsas vênulas. Soros apicais nos segmentos ou nas terminações das vênulas laterais; indúsio

\footnotetext{
${ }^{1}$ Museu Paraense Emílio Goeldi, Prog. Capacitação Institucional, Av. Perimetral 1901, Terra Firme, 66077-830, Belém, PA, Brasil

${ }^{2}$ Universidade Federal de Minas Gerais, Av. Antônio Carlos 6627, Pampulha, 31270-901, Belo Horizonte, MG, Brasil.

${ }^{3}$ Autor para correspondência: jujupallos@hotmail.com
} 
tubular, campanulado, livre ou imerso no tecido laminar, não bilabiado, com bordos expandidos ou não, sem células marginais escurecidas, com ou sem tricomas; receptáculo geralmente exserto.
Gênero monofilético, neotropical, com cerca de 60 espécies, com ao menos uma ocorrendo na África continental (Ebihara et al. 2006; PPG I 2016). Na área estudada ocorrem quatro espécies.

\section{Chave de identificação das espécies de Trichomanes das cangas da Serra dos Carajás}

1. Lâmina (3-)4-pinada; tecido laminar com mais de uma camada de células

1.3. Trichomanes elegans

1'. Lâmina profundamente pinatífida a 1-pinada; tecido laminar com apenas uma camada de células .... 2

2. Margem da lâmina glabra; falsas vênulas abundantes

1.4. Trichomanes pinnatum

2'. Margem da lâmina com tricomas; falsas vênulas ausentes ... 3

3. Caule longo, subereto; pecíolo inconspicuamente alado; segmentos basais deflexos

3'. Caule curto, cespitoso; pecíolo sem alas; segmentos basais perpendiculares à raque 1.1. Trichomanes accedens 1.2. Trichomanes crispum

1.1. Trichomanes accedens C.Presl., Abh. Königl. Böhm. Ges. Wiss., ser. 5: 374. 1851. Fig. 1a

Plantas rupícolas. Caule longo, subereto. Frondes 12-40 cm compr., eretas, monomorfas; pecíolo 4-12 cm compr., (inconspicuamente) alado, com tricomas; lâmina profundamente pinatífida, linear-lanceolada, com apenas uma camada de células, tricomas sobre os eixos em ambas as faces, margem crenulada, com tricomas; raque alada, ala estreita na base, alargando-se em direção ao ápice; segmentos linear-lanceolados, com os pares basais deflexos; venação pinada, furcada, sem falsas vênulas. Soros 2-5 no ápice dos segmentos; indúsio imerso no tecido laminar, bordo levemente expandido, com tricomas.

Material selecionado: Canaã dos Carajás, Serra Sul, S11D, 06²3'49”S, 50²0'26”W, 25.I.2012, A.J. Arruda et al. 464 (BHCB).

Material adicional examinado: BRASIL. PARÁ: Faro, Floresta Estadual de Faro, margem esquerda do Rio Nhamundá, $01^{\circ} 42$ '23”S, 57¹2'10”W, 60 m, 17.I.2008, M.R. Pietrobom \& G. Teixeira 7292 (MG).

Trichomanes accedens pode ser reconhecida por possuir pecíolo alado e pelos últimos pares de pinas basais deflexos. Contudo, as estreitas alas na porção distal do pecíolo são frequentemente danificadas na coleta e manuseio do material, o que pode dificultar a sua visualização.

Espécie com distribuição neotropical, ocorrendo no Brasil, Colômbia, Guiana, Guiana Francesa, Peru, Suriname, Trindade e Tobago e Venezuela (Windisch 1988). Brasil: AM, AP, BA, MT e PA (Prado et al. 2015). Serra dos Carajás: Serra Sul: S11D. Na Serra dos Carajás ocorre preferencialmente em paredões rochosos próximos à cachoeiras, em locais sombreados na Floresta Ombrófila Densa, entre 250-750 m de altitude.

1.2. Trichomanes crispum L., Sp. Pl. 2: 1097. 1753.

Fig. $1 \mathrm{~b}$

Plantas rupícolas. Caule curto, cespitoso. Frondes 7-16 cm compr., levemente arqueadas, monomorfas; pecíolo 1-2 cm compr., não alado, com tricomas; lâmina 1-pinada na porção proximal, pinatífida distalmente, linear-lanceolada a linearoblonga, com apenas uma camada de células, tricomas sobre os eixos em ambas as faces, margem crenulada, com tricomas; raque alada em toda a sua extensão ou somente na porção distal; segmentos linear-lanceolados a linear-oblongos, com os pares basais perpendiculares à raque; venação pinada, furcada, sem falsas vênulas. Soros 1-3(-4) no ápice dos segmentos; indúsio imerso no tecido laminar, bordo levemente expandido, com tricomas.

Material selecionado: Canaã dos Carajás, Serra Sul, 06²4'44”S, 50¹9'56"W, 650 m, 02.X.2009, P.L. Viana et al. 4346 (BHCB). Parauapebas, Serra Norte, N1, 0602'19”S, 50¹7'32'W, 08.II.2012, L.F.A de Paula et al. $526(\mathrm{BHCB})$.

Material adicional examinado: BRASIL. PARÁ: Almeirim, Reserva Biológica Maicuru, 0048'56"S, 5356'31”W, 214 m, 26.X.2008, M.G.C. Souza \& S. Maciel 170 (MG).

Trichomanes crispum é uma espécie extremamente polimorfa que se assemelha bastante à T. pilosum Raddi, espécie que ocorre no Cerrado e Mata Atlântica e à T. cristatum Kaulf., espécie que ocorre na Amazônia e Mata Atlântica. Diferencia-se de $T$. pilosum por possuir o bordo do indúsio uniformemente expandido, enquanto $T$. 
pilosum possui o bordo com lobos laterais formados pelo tecido laminar que acompanha as nervuras laterais do indúsio (Windisch 1996). Diferencia-se de $T$. cristatum por possuir caule cespitoso e frondes arqueadas com ca. 7-16 cm compr., enquanto $T$. cristatum possui caule curto-reptante e frondes eretas com ca. 20-50 cm compr.

Espécie com distribuição neotropical, ocorrendo na América Central, Antilhas, Brasil, Colômbia, Guiana, Guiana Francesa, México, Suriname, Trindade e Tobago e Venezuela (Mickel \& Smith 2004). Brasil: AC, AM, AP, CE, MA, PA, RO e RR (Prado et al. 2015). Serra dos Carajás: Serra Norte: N1 e Serra Sul, ocorrendo preferencialmente em grutas e cavernas de canga, ou no interior da Floresta Ombrófila Densa e Floresta Ombrófila Aberta, em locais sombreados e associados a cursos d'água, entre 600-700 m de altitude.

\subsection{Trichomanes elegans Rich.}

Fig. 1c

Plantas terrícolas ou rupícolas. Caule curto, ereto. Frondes 10-55 cm compr., eretas, monomorfas; pecíolo 5-30 cm compr., alado na porção distal, com tricomas; lâmina (3-)4-pinada, deltoide, com mais de uma camada de células, tricomas sobre os eixos em ambas as faces, margem crenulada, com tricomas; raque alada, ala estreita na base, alargandose em direção ao ápice; pinas lanceoladas, últimos segmentos laciniados; venação pinada, cada um dos últimos segmentos com uma única vênula, falsas vênulas ausentes. Soros numerosos em ambas as margens dos segmentos; indúsio tubular, livre, séssil a curto-pedicelado, bordo truncado ou levemente expandido, glabro.

Material selecionado: Canaã dos Carajás, Serra Sul, 6²0'59'S, 50²5'49'”, 688 m, 14.II.2010, T.E. Almeida et al. 2185 (BHCB). Parauapebas, Serra Norte, N1, 602'19'’S, 50¹7'32'”W, 677 m, 08.II.2012, A.J. Arruda et al. 553 (BHCB).

Material adicional examinado: BRASIL. AMAZONAS: Carauari, noroeste do Rio Juruá, 28.IV.1980, A.S.L. Silva et al. 402 (MG).

Trichomanes elegans diferencia-se das demais espécies congenéricas neotropicais por possuir tecido laminar com mais de uma camada de células. Quando viva, esta espécie possui coloração azulesverdeada metálica, contudo, após herborizada, é comum tornar-se enegrecida.

Espécie com distribuição neotropical, ocorrendo nas Antilhas, Bolívia, Brasil, Colômbia, Costa Rica, Equador, Guiana, Guiana Francesa, Nicarágua, Panamá, Peru e Suriname (Smith 1995). Brasil: AC, AM, AP, BA, ES, MG, MT, PA, PR, RJ, RO, RR, SC e SP (Prado et al. 2015). Serra dos
Carajás: Serra Norte: N1 e Serra Sul, ocorrendo preferencialmente em fundo de vales e em campos graminosos, ou no interior da Floresta Ombrófila Densa, associada a cursos d'água, entre 500-700 $\mathrm{m}$ de altitude.

1.4. Trichomanes pinnatum Hedw., Fil. Gen. Sp., t.4, f.1. 1799.

Fig. 1d

Plantas terrícolas ou rupícolas. Caule curtoreptante. Frondes 20-50 cm compr., eretas, monomorfas a levemente subdimorfas; pecíolo 8-30 cm compr., não alado, glabrescente; lâmina 1-pinada, deltoide a amplamente ovada, com apenas uma camada de células, tricomas esparsos sobre os eixos principais na superfície abaxial, margem denteada, glabra; raque alada apenas na porção distal, casualmente possuindo ápice flageliforme; pinas lineares, linear-lanceoladas ou estreitamente oblongas; venação pinada, furcada, unidas no ápice por uma nervura coletora, falsas vênulas abundantes. Soros numerosos em ambas as margens das pinas; indúsio tubular, livre, séssil a curto-pedicelado, bordo truncado a bilobado, glabro.

Material selecionado: Canaã dos Carajás, Serra Sul, 06²2'18'S, 50²3'05'W, 750 m, 08.X.2007, P.L. Viana et al. 3401 (BHCB); Serra do Tarzan, 06¹9'34"'S, 5007'13”W, 737 m, 09.II.2012, L.F.A. de Paula et al. 534 (BHCB). Parauapebas, Serra Norte, 06 04 '22'S, 50¹1'42”'W, 505 m, 24.III.2012, A.J. Arruda et al. 814 (BHCB); Águas Claras, 06¹0'23”S, 50²1'08'W, 423 m, 26.III.2012, A.J. Arruda et al. 870 (BHCB); Serra da Bocaina, 06¹8'46”S, 4952'59''W, 672 m, 28.I.2013, A.J. Arruda et al. 1404 (BHCB).

Material adicional examinado: BRASIL. PARÁ: Melgaço, Estação Científica Ferreira Penna, plote 2 do Projeto TEAM, 08.XI.2004, P. Sanjuan \& M.R. Pietrobom 402 (MG).

Trichomanes pinnatum, quando estéril, pode ser confundida com T. vittaria D.C. ex Poir., pelo formato da lâmina, bem como por possuir falsas vênulas abundantes. Quando férteis, diferenciamse facilmente por $T$. pinnatum possuir fronde fértil pinada, deltoide a amplamente ovada, enquanto T. vittaria possui fronde fértil simples e linear. Diferencia-se ainda de T. hostmannianum (Klotzsch) Kunze, outra espécie amazônica, por esta última não possuir falsas vênulas entre as nervuras.

Espécie com distribuição neotropical, ocorrendo nas Antilhas, Belize, Bolívia, Brasil, Colômbia, Costa Rica, Equador, Guatemala, Guiana, Guiana Francesa, Honduras, México, Nicarágua, Panamá, Peru, Suriname e Venezuela (Mickel \& Smith 2004). Brasil: todos os estados, exceto PR, RJ, RN, RS, SC, SE e SP (Prado et al. 2015). 

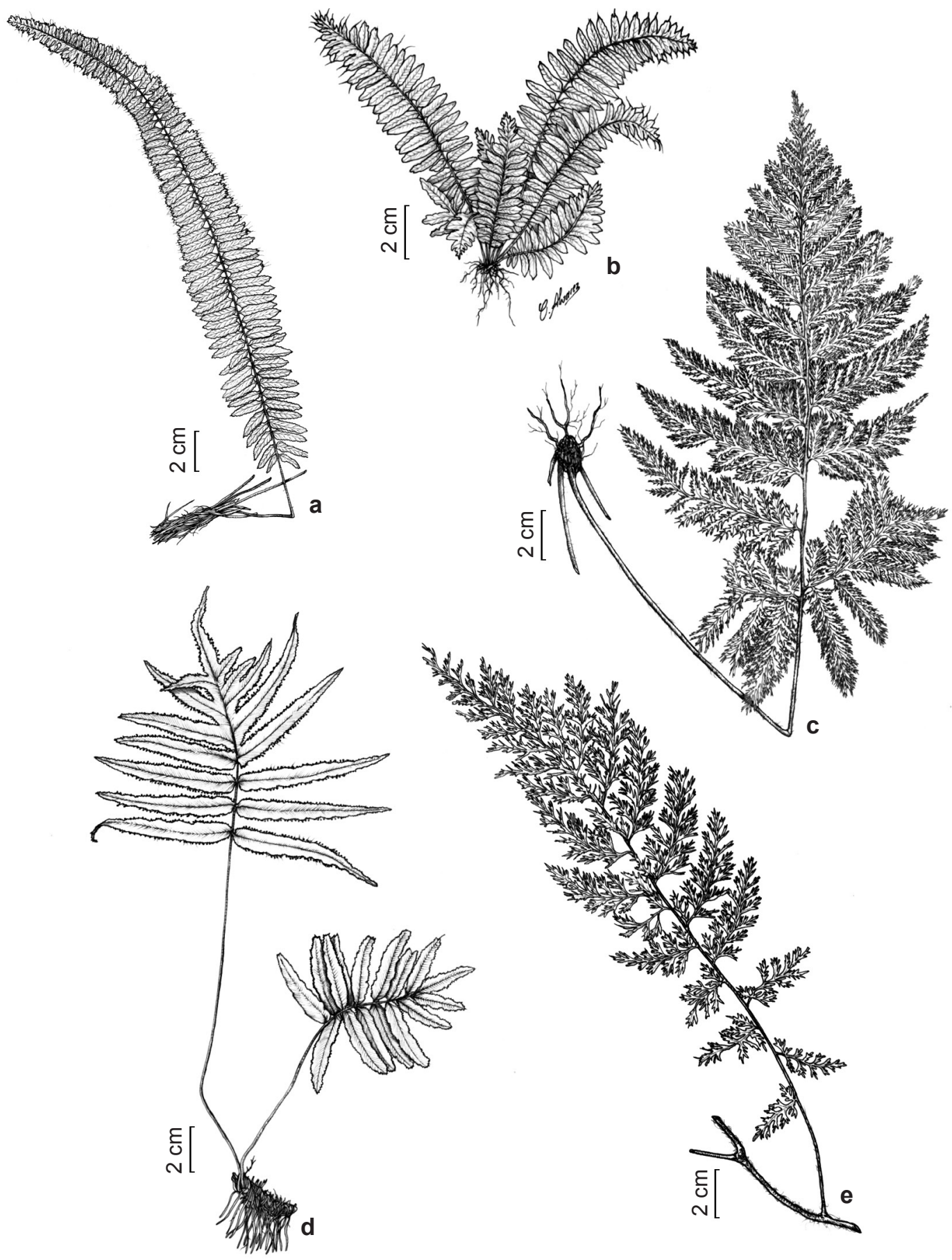

Figura 1 - a. Trichomanes accedens - hábito. b. Trichomanes crispum - hábito. c. Trichomanes elegans - hábito. d. Trichomanes pinnatum - hábito. e. Vandenboschia radicans - hábito (a. Pietrobom \& Teixeira 7292; b. Souza \& Maciel 170; c. Silva et al. 402; d. Sanjuan \& Pietrobom 402; e. Secco et al. 477).

Figure 1 - a. Trichomanes accedens - habit. b. Trichomanes crispum - habit. c. Trichomanes elegans - habit. d. Trichomanes pinnatum - habit. e. Vandenboschia radicans - habit (a. Pietrobom \& Teixeira 7292; b. Souza \& Maciel 170; c. Silva et al. 402; d. Sanjuan \& Pietrobom 402; e. Secco et al. 477). 
Serra dos Carajás: Serra Norte, Serra Sul, Serra da Bocaina e Serra do Tarzan. Na Serra dos Carajás ocorre preferencialmente em matas baixas e campos graminosos, ou no interior da Floresta Ombrófila Densa, associada a cursos d'água e cachoeiras, entre $500-750 \mathrm{~m}$ de altitude.

2. Vandenboschia Copel., Philipp. J. Sci. 67(1): 51. 1938.

Plantas terrícolas ou epífitas. Caule longoreptante, irregularmente ramificado, Frondes monomorfas; pecíolo alado, com tricomas; lâmina 2-pinada a 3-pinado-pinatífida, com tricomas; venação livre, furcada, anadrômica, sem falsas vênulas. Soros nas terminações das vênulas laterais; indúsio cônico, livre ou imerso no tecido laminar, bilabiado, sem células marginais escurecidas, sem tricomas; receptáculo longamente exserto. Gênero monofilético, pantropical, com cerca de 15 espécies, algumas destas alcançando as regiões temperadas do hemisfério norte (Ebihara et al. 2006; PPG I 2016). $\mathrm{Na}$ área estudada ocorre uma espécie.

2.1. Vandenboschia radicans (Sw.) Copel., Philipp. J. Sci. 67(1): 54. 1938.

Trichomanes radicans Sw., J. Bot. (Schrader) 1800(2): 97. 1801.

Fig. 1e

Plantas terrícolas ou rupícolas. Caule longoreptante. Frondes 15-40 cm compr., monomorfas; pecíolo 5-12 cm compr., alado, com tricomas; lâmina 2-pinada a 3-pinado-pinatífida, lanceolada, oblongo-lanceolada ou ovada, com tricomas clavados sobre os eixos na superfície abaxial, margem inteira; raque alada; pinas ovadas a ovado-lanceoladas; venação pinada, furcada, sem falsas vênulas. Soros numerosos; indúsio livre ou levemente imerso no tecido laminar, bordo truncado a lobado, glabro.

Material selecionado: Canaã dos Carajás, Racha Placa, Serra Sul, 06²5'48'S, 50¹9'38'W, 409 m, 01.V.2010, T.E. Almeida et al. 2361 (BHCB); Serra do Tarzan, 06 20'58'S, 5007'19”'W, 428 m, 16.VI.2012, L.V.C. Silva et al. 1347 (BHCB). Parauapebas [Marabá], Serra Norte, N1, 16.III.1985, R.S. Secco et al. 477 (MG).

Vandenboschia radicans caracteriza-se pelo caule longo-reptante com tricomas multicelulares marrom-escuros e brilhantes, frondes espaçadas (ca. $4 \mathrm{~cm}$ ) com pecíolos portando tricomas catenados, especialmente na porção basal.

Espécie com distribuição sub-cosmopolita, ocorrendo na África, Antilhas, Ásia, Bolívia, Brasil, Colômbia, Costa Rica, El Salvador, Equador, Europa, Guatemala, Guiana, Guiana Francesa, Honduras, México, Nicarágua, Panamá,
Paraguai, Peru, Suriname e Venezuela (Mickel \& Smith 2004). Brasil: AM, BA, ES, MG, MT, PA, PR, RJ, RR, RS, SC e SP (Prado et al. 2015). Serra dos Carajás: Serra Norte, Serra Sul e Serra do Tarzan, preferencialmente no interior da mata, em áreas associadas a cursos d'água, entre 250-750 $\mathrm{m}$ de altitude.

\section{Agradecimentos}

Agradecemos ao CNPq, a bolsa DTI-B concedida a J. Pallos (proc. 380559/2016-1), a bolsa PCI-DB concedida a L.A.A. Góes-Neto (proc. 300008/2017-1), bem como a bolsa de Produtividade para A. Salino (proc. 306868/2014-8). A Carlos Alvarez, a confecção das ilustrações. Ao projeto objeto do convênio MPEG/ITV/FADESP (proc. 01205.000250/2014-10) e ao projeto aprovado pelo CNPq (proc. 455505/2014-4), o financiamento.

\section{Referências}

Arruda AJ (2014) Samambaias e licófitas das serras ferruginosas da Floresta Nacional de Carajás, Pará, Brasil. Dissertação de Mestrado. Universidade Federal de Minas Gerais, Belo Horizonte. 224p.

Ebihara A, Dubuisson J-Y, Iwatsuki K, Hennequin S \& Ito M (2006) A taxonomic revision os Hymenophyllaceae. Blumea 51: 221-280.

Mickel JT \& Smith AR (2004) The Pteridophytes of Mexico. Memoirs of the New York Botanical Garden 88: 1-1055.

PPG I 2016. A community-derived classification for extant lycophytes and ferns. Journal of Systematics and Evolution 54: 563-603.

Prado J, Sylvestre LS, Labiak PH, Windisch PG, Salino A, Barros ICL, Hirai RY, Almeida TE, Santiago ACP, Kieling-Rubio MA, Pereira AFN, Øllgaard B, Ramos CGV, Mickel JT, Dittrich VAO, Mynssen CM, Schwartsburd PB, Condack JPS, Pereira JBS \& Matos FB (2015) Diversity of ferns and lycophytes in Brazil. Rodriguésia 66: 1073-1083.

Smith AR (1995) Hymenophyllaceae. In: Berry PE, Holst BK \& Yatskievych K (eds.) Pteridophytes, Spermatophytes: Acanthaceae-Araceae. In: Steyermark JS, Berry PE \& Holst BK (eds.) Flora of the Venezuelan Guayana. Vol. 2. Timber Press, Portland. Pp. 159-185.

Smith AR, Pryer KM, Schuettpelz E, Korall P, Schneider H, Wolf PG (2006) A classification for extant ferns. Taxon 55: 705-731

Windisch PG (1988) Sinopse das espécies do grupo de Trichomanes crispum L. (Pteridophyta, Hymenophyllaceae) ocorrentes na Amazônia brasileira. Bradea 5: 55-58.

Windisch PG (1996) Pteridófitas do estado de Mato Grosso: Hymenophyllaceae. Bradea 6: 400-423. 


\section{Lista de exsicatas}

Almeida TE 2163 (1.4), 2185 (1.3), 2268 (1.2), 2361 (2.1), 2465 (2.1). Arruda AJ 185 (1.4), 346 (1.4), 464 (1.1), 465 (1.4), 476 (1.4), 553 (1.3), 667 (1.4), 814 (1.4), 821 (1.3), 870 (1.4), 1104 (1.4), 1129 (1.4), 1141 (1.3), 1147 (1.4), 1150 (2.1), 1169 (1.3), 1170 (1.4). Costa LV 928 (1.4). Giorni VT 272 (1.4). Mota NFO 1104 (1.2), 1958 (1.4). de Paula LFA 526 (1.2), 531 (1.4), 534 (1.4), 557 (1.4). Silva LVC 1347 (2.1). Souza DT 1095 (2.1), 1097 (1.4), 1116 (1.4), 1167 (2.1). Pietrobom MR 7292 (1.1). Sanjuan P 402 (1.4). Secco RS 477 (2.1). Silva ASL 402 (1.3). Souza MGC 170 (1.2).Viana PL 3401 (1.4), 4071 (1.4), 4160 (1.4), 4346 (1.2), 4348 (1.4). 